\title{
LIFE AT THE EDGE: IS FOOD QUALITY REALLY OF MINOR IMPORTANCE AT LOW QUANTITIES?
}

\author{
MaArten Boersma $^{1,2,3}$ And Christian Kreutzer ${ }^{1}$ \\ ${ }^{1}$ Max-Planck-Institut für Limnologie, Postfach 165, D-24306 Plön, Germany \\ ${ }^{2}$ Alfred-Wegener-Institut für Polar und Meeresforschung, Biologische Anstalt Helgoland, Postfach 180, \\ 27483 Helgoland, Germany
}

\begin{abstract}
There is increasing evidence that the quality of nutrient-limited algae is suboptimal for zooplankton production. These effects of nutrient limitation are supposed to be important mainly at higher concentrations of food because at lower quantities the overall energetic limitation of body growth should hide the effect of mineral limitations. This has been hypothesized in a variety of papers, but experimental evidence is still weak. In the present study we carried out a set of growth experiments investigating the effect of food quality at very low food levels ranging from $30 \mu \mathrm{g} \mathrm{C} / \mathrm{L}$ up to $150 \mu \mathrm{g} \mathrm{C} / \mathrm{L}$. In all of the experiments, the growth rates of Daphnia magna neonates were lower when grown on P-limited Scenedesmus obliquus. This effect disappeared when phosphorus was added to the P-limited algae prior to feeding, indicating that mineral limitation can occur even at very low levels of food.

Neonates born to mothers raised on either high- or low-P Scenedesmus were analyzed for body mass and lipid content as well as mass-specific phosphorus content to check for possible differential investment into neonates in different environments. Although massspecific phosphorus content was higher in animals born from mothers grown on high-P algae, when fed low quantities of P-limited algae, growth rates of neonates born under low$\mathrm{P}$ conditions were higher than those of animals born under high-P conditions. This can be explained by an increased body lipid content of low-P neonates, even though there were no differences in neonate body mass between treatments.

These results illustrate the importance of the incorporation of low food concentrations in ecological stoichiometry models.
\end{abstract}

Key words: Daphnia; food concentration; nutrient; phosphorus; stoichiometry; threshold concentration.

\section{INTRODUCTION}

Secondary producers generally take up their food in packages and not as single nutrients. As prey items normally do not have the same nutrient requirements as their predators, nutritional imbalances of the food occur regularly. This imbalance is particularly clear at the primary producer-herbivore interface, as plants contain a surplus of carbon relative to nitrogen or phosphorus, to the extent that animals are thought to be limited by nitrogen in many terrestrial and marine environments (Roman 1983, White 1993) and by phosphorus in freshwater systems (DeMott and Gulati 1999). Obviously, the surplus carbon will dissipate through the food chain as it is needed as an energy source, but the implication is that many consumers will have more problems meeting their nutrient demands than their energy requirements.

Ecological stoichiometry, the study of the balance of energy and multiple chemical elements in ecology,

Manuscript received 16 April 2001; revised 21 November 2001; accepted 5 December 2001; final version received 4 January 2002 .

${ }^{3}$ Address for correspondence:

E-mail: mboersma@awi-bremerhaven.de has been applied successfully to explain differences in quality between different food sources, especially in aquatic systems (Sterner et al. 1998, Elser and Urabe 1999, Sterner and Elser 2002), whereas there has been little comparable work on terrestrial communities (Elser et al. 2000). In terrestrial systems mostly single nutrients have been used as a measure of foraging success, with carbon (energy) as the main currency in studies on vertebrate feeding behavior (Schoener 1971), and nitrogen as the main limiting nutrient considered by insect nutritional ecologists (e.g., Joern and Behmer 1998). Stoichiometry theory predicts that animal growth and nutrient recycling should be tightly coupled with resource nutrient ratios (Sterner and Hessen 1994, Elser et al. 1996). Consumers should release much of the nutrients present in excess, while retaining most of the limiting nutrient, under the assumption that the consumer will try to maintain homeostasis in its own tissue. This coupling implies that the quality of a certain resource is determined solely by its nutrient ratio compared to the requirements of the consumer, and that organisms should be highly efficient in the uptake and retention of the limiting nutrient (e.g., Raubenheimer and Simpson 1998). Thus, theoretically, excretion of the limiting nutrient should approach zero as the car- 
bon : nutrient ratio increases in the food (Anderson 1992, but see Andersen 1997). The evidence to back up this assumption of potential $100 \%$ nutrient utilization efficiencies is, however, weak. Olsen et al. (1986) implied such a relationship in a model study of the cladoceran Daphnia, and Thingstad (1987) did the same for bacteria. The experimental evidence, however, is less clear. Sugiura et al. (2000) observed that trout raised under phosphorus-limited conditions did not excrete phosphorus, but marine copepods use nitrogen with an efficiency of only $40 \%$, even when supplied with high C:N food (LeBorgne 1986, Anderson and Hessen 1995). In addition, many terrestrial organisms continue to release the limiting nutrient even under severe limitation (e.g., Slansky and Feeny 1977, Partridge et al. 1989). One reason for this continued release of the limiting nutrient might be the increase in feeding activity that is very often observed to occur on food of low nutrient content, and which results in a decrease in retention efficiency (Tabashnik 1982, Grimm 1988, Reynolds 1990), but excretion of the limiting nutrient under severe limitation also occurs (DeMott et al. 1998).

This excretion and suboptimal use of nutrients even when consumers are severely limited has several consequences for our understanding of the processes that play a role in the producer-consumer interface. It is generally accepted that, whereas carbon is required for both new biomass and energy, nutrient elements fulfill primarily a structural role. This implies that at food levels below the maintenance threshold, the mineral content of the food should not play a role, as materials for biomass gain are irrelevant under low food quantity, and the animals only need carbon (energy) for their maintenance (Hessen 1992, Urabe and Watanabe 1993). This consequence of the stoichiometry models has not been tested experimentally very often, and only once formally (Sterner and Robinson 1994). Kilham et al. (1997) observed quality differences between different food sources for Daphnia even at low food concentrations, as did Lampert (1977). In contrast, Vos et al. (2000) observed that energy content of the food seemed to be more important at lower food concentrations than mineral content in early instar larvae of the midge Chironomus riparius. Sterner and Robinson (1994) reported no differences in growth between Daphnia magna individuals fed very low concentrations of phosphorus-limited and phosphorus-sufficient algae, as did Rothhaupt (1995) in a study with the rotifer Brachionus rubens. Based on this, Sterner and Robinson concluded that indeed differences in mineral content of the food do not play a role when food concentrations are low. However, as the premise of the $100 \%$ retention efficiency of the stoichiometry models seems to falter, and animals still excrete considerable amounts of the limiting nutrient, there is no real theoretical ground to expect that the mineral content of the food should not be of importance at low food quan- tities. The significance of limiting nutrients at low food levels is of vital importance for our understanding of maintenance metabolism (e.g., Kooijman 2000). Therefore it is essential to reassess the importance of mineral content differences at low food levels, especially since the study of Sterner and Robinson (1994) was based on relatively small sample sizes. Hence, the hypothesis we examine is that mineral limitation is not important to growth when food is scarce because energy is more important under these conditions, and basic energydriven metabolic needs must be satisfied first. We investigate this using the cladoceran Daphnia magna as a model system.

One of the other premises in ecological stoichiometry theory to date is the strict homeostasis of the consumers. This homeostasis introduces the linearity in stoichiometric models (Kooijman 1995), which makes them mathematically simpler (Sterner 1997). However, even in aquatic systems, where stoichiometric approaches have been primarily used (Elser and Hassett 1994, Anderson and Pond 2000, Touratier et al. 2001), the homeostasis assumption does not seem to hold completely. Cladocerans (DeMott et al. 1998, Plath and Boersma 2001), copepods (Walve and Larsson 1999), and fish (Sterner and George 2000) all change the relative composition of their body tissue more or less dramatically when fed different food sources. Moreover, allometric differences, i.e., differences in the stoichiometry between animals of different sizes and ages, have also been found (DeMott et al. 1998, Sterner and George 2000), which suggests that there might be differential investment in somatic and reproductive growth. Although the subject of allocation to reproduction has been a topic of interest for many years in many organisms (e.g., Lack 1947, Smith and Fretwell 1974, Stearns 1976, Congdon and Gibbons 1987, Boersma 1997a, Glazier 2000), most of these studies focused on energy as the only available resource. The main interest was to explain how the available energy was divided up between and among clutches, and although there is a wealth of information available on the effect of differences in food quality supplied to mothers on investment in offspring, this is usually restricted to the number of eggs produced or the mass of individual eggs (e.g., Nager et al. 1997, Joern and Behmer 1998, Urabe and Sterner 2001). However, given the relaxation of the assumption of perfect homeostasis, we set out to investigate whether mothers do indeed supply their offspring with different amounts of nutrients based on their own feeding history, and also to assess the consequences of these differences for the fitness of their offspring.

\section{Material And Methods \\ Growth experiments}

In the first part of this study we investigated the resource-dependent growth of Daphnia magna neo- 

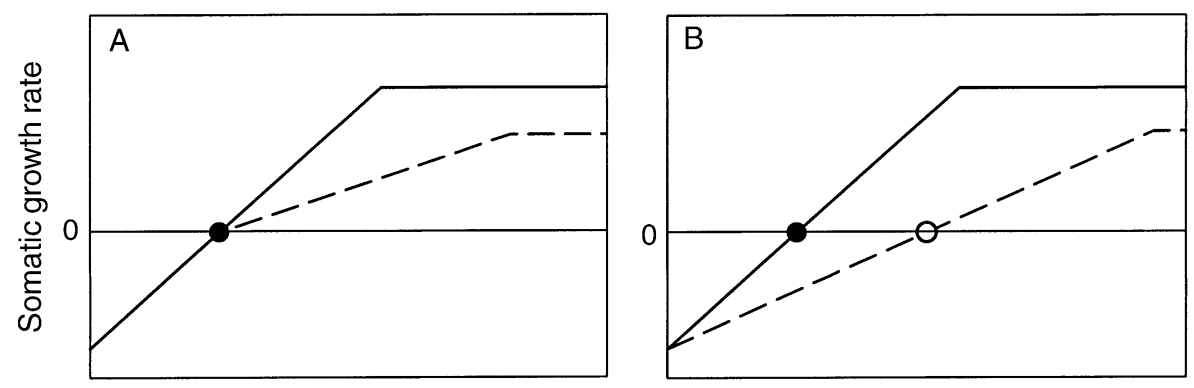

Food quantity

FIG. 1. Hypothetical dependence of body growth on food nutrient content and quantity (redrawn from Sterner and Robinson [1994]). Basic metabolic costs (threshold food concentrations; $C_{0}$ ) are indicated by circles (solid = high-nutrient food; open $=$ low-nutrient food). (A) Identical values for $C_{0}$ should occur if only energy and no nutrients are required for maintenance metabolism. (B) Differences in threshold values are expected if the animals do require phosphorus even at very low food concentrations. Solid lines = high-nutrient food; dashed lines = low-nutrient food.

nates at very low levels of food of different specific phosphorus content. The daphniids originated from long-established stock cultures at the Max-Planck-Institute in Plön, Germany. During all phases of the experiments and the precultivation they were kept in an artificial, phosphorus-free medium (ADaM) (Klüttgen et al. 1994). Prior to each experiment, several females were raised separately in $200-\mathrm{mL}$ jars from neonates to adults and fed P-sufficient green algae, Scenedesmus obliquus (formerly known as $S$. acutus), at concentrations $>1 \mathrm{mg} \mathrm{C} / \mathrm{L}$. The daphniids were transferred to clean jars at regular intervals and third-brood neonates released within $24 \mathrm{~h}$ were used for the experiments. Neonates from several mothers were pooled and then distributed randomly to the experimental vessels, and a random subsample was taken to estimate initial mass. The experiments were carried out in a flow-through culture system similar to the one described by Lampert et al. (1988). Flow-through vessels with a volume of $120 \mathrm{~mL}$ were kept at $20^{\circ} \mathrm{C}$ in a water bath under continuous dim light. Fresh food suspensions were prepared daily and added to the vessels at a flow rate of $1 \mathrm{~L} / \mathrm{d}$. Food reservoirs were kept dark and stirred gently to avoid sedimentation of the algae. During the experiments, the animals were fed $S$. obliquus grown either on low- $(83.7 \mu \mathrm{g}$ P/L) or high- (1.395 mg P/L) phosphorus Z/4 medium (Zehnder and Gorham 1960) in semicontinuous chemostat cultures, with a dilution rate of $\sim 0.1 \mathrm{~d}^{-1}$. In order to establish the importance of the direct phosphorus limitation of algae, we had an additional treatment where we added dissolved phosphorus to the P-limited algae just before feeding them to the animals (DeMott 1998, Boersma 2000, Plath and Boersma 2001). Every morning, the particulate organic carbon (POC) content of the chemostat suspensions was measured by filtering an aliquot on $\mathrm{GF} / \mathrm{F}$ filters. These filters were dried for $2 \mathrm{~h}$ at $100^{\circ} \mathrm{C}$ and afterwards analyzed in a LECO carbon analyzer (LECO, St. Louis, Missouri). An appropriate amount of algal suspension was then diluted with ADaM to the desired carbon concentration. At the same time we also analyzed the particulate phosphorus concentration of the algal suspensions. The C:P ratios for high-phosphorus (200) and low-phosphorus (1200) algae were constant throughout the experiments.

Somatic growth rates were measured at five food levels ranging from $30 \mu \mathrm{g} \mathrm{C} / \mathrm{L}$ up to $150 \mu \mathrm{g} \mathrm{C} / \mathrm{L}$. The amounts of phosphorus pulsed to the different food emulsions ranged from $0.465 \mu \mathrm{g} / \mathrm{L}(30 \mu \mathrm{g} \mathrm{C} / \mathrm{L})$ to $2.325 \mu \mathrm{g} / \mathrm{L}(150 \mu \mathrm{g} \mathrm{C} / \mathrm{L})$ to ensure that the algal C:P ratios were similar for all different treatments. In each of the experiments, there were three replicate vessels per food concentration and mineral content; each of them contained five 1-d-old daphniids. After $3 \mathrm{~d}$, the animals were removed from the vessels, and placed together in weighing boats. The boats were dried overnight at $60^{\circ} \mathrm{C}$, and weighed to the nearest $0.1 \mu \mathrm{g}$. Dry masses were converted into somatic growth rates per day using the formula $g=\left(\ln \left[M_{3}\right]-\ln \left[M_{0}\right]\right) / 3$, where $M_{0}$ and $M_{3}$ are the masses of the animals at day zero and three, respectively, and 3 (days) is the duration of an experiment (Lampert and Trubetskova 1996).

Threshold food concentrations $\left(C_{0}\right)$, food concentrations that support zero somatic growth, give an indication of food levels at which a population is sustainable (Kreutzer and Lampert 1999). $C_{0}$ is calculated from somatic growth rates determined at different food levels, and as such integrates all of the available information in an experiment (Lampert 1977, Gliwicz 1990). In their work, Sterner and Robinson (1994) contrasted two different possible scenarios when animals are fed low concentrations of food (Fig. 1). If, at very low food levels, only energy for maintenance and not the nutrient content for growth of the food is of importance, the growth rate of the daphniids should be similar on the different food types until the food concentration is so high that it will sustain net growth. Differences in growth rates between low- and highnutrient food should be found only at food concentrations above $C_{0}$, i.e., the consumer switches from energy 
limitation to nutrient limitation (Fig. 1A). If the nutrient content of the food plays a role even if the energy content of the food is below the maintenance level, growth on the low-nutrient food should be lower, resulting in a higher threshold food concentration (Fig. 1B).

Two experiments were carried out, the only difference between them being that in the first experiment the neonates were born in the high-phosphorus food medium the mothers were kept in, and in the second experiment the mothers were transferred to food-free medium $24 \mathrm{~h}$ before the experiment was started. This was done to reduce potential $\mathrm{P}$ accumulation effects due to the feeding of the neonates on the high-P food during precultivation.

\section{Reproduction}

D. magna neonates were cultured in 1-L jars at high concentrations of high-P food during their juvenile phase at densities of 20 individuals/L. After the animals had released their second clutch of neonates, half of the adults were transferred to low-P food, whereas the other half still received the high-P algae. After 1 wk at the specific food conditions, mothers and neonates released within $24 \mathrm{~h}$ were analyzed for body mass and mass-specific $\mathrm{P}$ content. A series of $10 \times 10$ neonates and $10 \times 2$ mothers were pooled for the analysis; the entire experiment was carried out twice. In the second experiment we also determined body size and the area of visible body lipids for 10 neonates from each treatment using a video imaging system program AnalySIS 3.0 (Soft Imaging Systems, Münster, Germany) connected to a dissecting microscope.

To test for the effects of differential investment into reproduction, neonates born at the different food sources were used to assess somatic growth rates at either high $(1.0 \mathrm{mg} \mathrm{C} / \mathrm{L})$ or low $(0.1 \mathrm{mg} \mathrm{C} / \mathrm{L})$ quantities of low- or high-P Scenedesmus for $3 \mathrm{~d}$. The experiments were carried out in a flow-through system as described in Materials and Methods: Growth experiments, and somatic growths rates were determined in the same way as in the growth experiments.

\section{RESULTS}

\section{Growth experiments}

We observed significant differences in growth rates between the different concentrations and different food types in both growth experiments (two-way ANOVA; $P<0.001$ ). Animals fed high-P Scenedesmus mostly grew considerably better than those reared on low-P algae (Fig. 2). In the second experiment, the growth rates were lower than in the first one, which can be explained by the differences in the precultivation mode. As they were starved for $12 \mathrm{~h}$ on average, the animals in experiment 2 will have had lower energy reserves, leading to reduced overall growth rates, because they have to refill internal storage before further growth

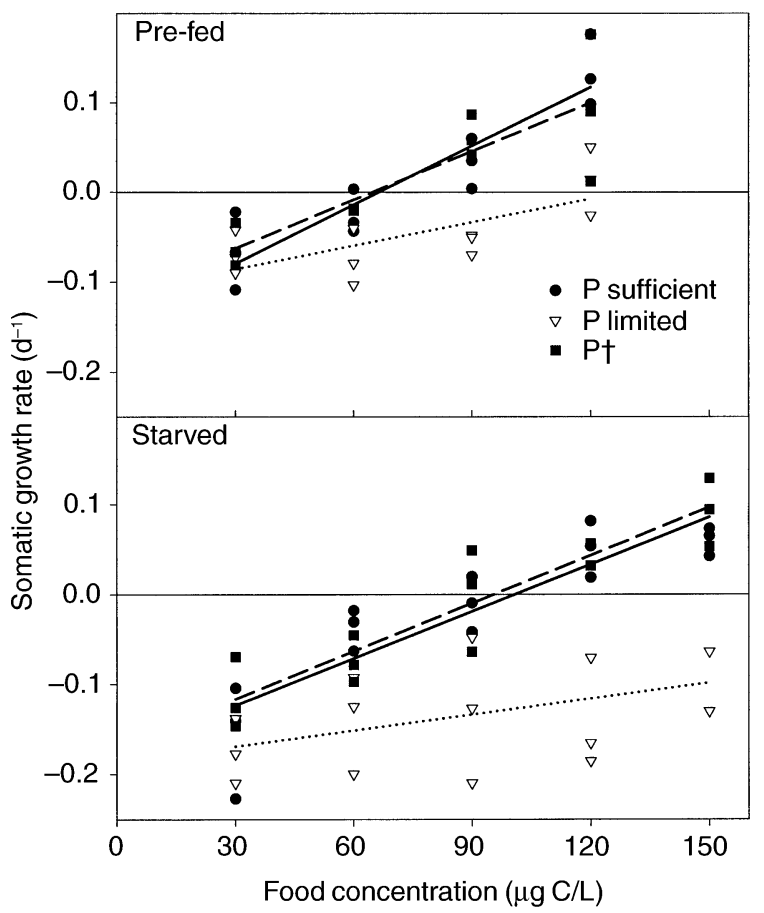

FIG. 2. Resource-dependent somatic growth rates $\left(\mathrm{d}^{-1}\right)$ of Daphnia magna neonates on high (P-sufficient), low (P-limited), or phosphorus-supplemented low-P (P $\dagger$ ) Scenedesmus obliquus calculated for a 3 -d period in experiment 1 (top panel), with pre-fed neonates; and experiment 2 (bottom panel) where the neonates were born in medium without food.

(McCauley et al. 1990, Bradley et al. 1991). A comparison of the growth rates under starvation conditions of pre-fed and starved animals over a period of $3 \mathrm{~d}$ supports this conclusion. The growth rates of pre-fed animals averaged $-0.0960 \pm 0.0370 \mathrm{~d}^{-1}$ (mean \pm 1 $\mathrm{SD})$, whereas the starved animals lost mass at a higher rate $\left(-0.170 \pm 0.0120 \mathrm{~d}^{-1}\right)$. This difference was highly significant $(P=0.004$, two-sample $t$ test $)$, and hence experiments one and two were not combined for further analysis.

Besides significant effects of both food concentration and mineral content, we also found a significant interaction of both effects $(P=0.027$ for experiment 1 and $P=0.05$ for experiment 2). Threshold food concentrations (Table 1) calculated from linear regression were two to three times lower at high-P food in both experiments $(64 \mu \mathrm{g} \mathrm{C} / \mathrm{L}, 104 \mu \mathrm{g} \mathrm{C} / \mathrm{L})$ than those in the low-P treatments $(127 \mu \mathrm{g} \mathrm{C} / \mathrm{L}, 311 \mu \mathrm{g} \mathrm{C} / \mathrm{L})$. As there were no overlaps of the $95 \%$ confidence intervals of the intersection point with the zero-growth axis, these results can be considered statistically significant. The addition of phosphorus to the low-P algae significantly increased growth of the animals compared to the nonsupplemented P-limited food (Tukey's hsd, $P$ $<0.006$ for experiment 1 and $P<0.0001$ for experiment 2), resulting also in lower threshold values (Table 1). In fact, the increase in growth rates as a result of 
TABLE 1. Threshold food concentrations $\left(C_{0}\right)$ for somatic growth of Daphnia magna cultured with Scenedesmus obliquus of different mineral content (P sufficient, P limited, and $\mathrm{P}$ limited with pulses of dissolved $\mathrm{P}$, just before feeding them to the daphniids [P pulsed]) in experiments 1 and 2 .

\begin{tabular}{clc}
\hline \hline Experiment & Treatment & $\begin{array}{c}\text { Threshold food } \\
\text { concentration }(\mu \mathrm{g} \mathrm{C} / \mathrm{L})\end{array}$ \\
\hline 1 & P sufficient & $64(54-76)$ \\
& P limited & $127(99-252)$ \\
2 & P pulsed & $65(46-79)$ \\
& P sufficient & $104(86-115)$ \\
& P limited & $311(195-\mathrm{ud})$ \\
& P pulsed & $95(83-105)$ \\
\hline
\end{tabular}

Note: Intersections of the $95 \%$ confidence intervals are given in parentheses (ud $=$ undefined).

the $\mathrm{P}$ addition was such that we did not see any differences between the growth rates of the pulsed animals and those that were kept at high-P algae, suggesting that at these low food levels the difference in quality between low-P and high-P algae can be explained solely by the difference in $\mathrm{P}$ content (Table 1; Fig. 2). Hence, these results show that even at low food levels, quality differences of algae do play a role.

Because the interactions between food concentration and food type were significant, one could argue that as a result the growth rates at all food levels should be different, even though one might not be able to see this at the lower concentrations, because the growth rates were so close together. Alternatively, one could assess food quantity value at which significant differences between food types could be found. Post hoc tests (Tukey hsd) revealed that, compared to the low-P treatment, daphniids receiving high-P food grew significantly better at $90 \mu \mathrm{g} \mathrm{C} / \mathrm{L}(P=0.05)$ and $120 \mu \mathrm{g} \mathrm{C} / \mathrm{L}(P=$ $0.004)$ in experiment 1 , and at $120 \mu \mathrm{g} \mathrm{C} / \mathrm{L}(P=0.002)$ and $150 \mu \mathrm{g} \mathrm{C} / \mathrm{L}(P=0.03)$ in the second experiment.

\section{Reproduction}

As was the case in the growth experiments with neonates, we also found food-dependent differences between adult D. magna grown at high levels of either high- or low-P S. obliquus. The animals reared for 1 wk at high-P food were not only significantly heavier than their sisters grown at P-limited algae, but also had an increased mass-specific P content (Table 2). Whereas the difference in body mass was a factor of two, differences in specific $\mathrm{P}$ content were less pronounced. In contrast to their mothers, neonates did not differ in body mass and had an average dry mass of nearly 8 $\mu \mathrm{g}$ in both treatments (Table 2). Interestingly, significant differences occurred in the mass-specific $\mathrm{P}$ content of the offspring (Table 2). Neonates born at low-P food had a mineral content of $0.007 \pm 0.001 \mu \mathrm{g} P / \mu \mathrm{g}$ dry mass, compared to the high-P treatment $(0.009 \pm 0.002$ $\mu \mathrm{g} P / \mu \mathrm{g}$ dry mass). Independent of food quality, neonates in both treatments had an increased specific $P$ content compared to their mothers, and this trend was stronger in the low-P treatment. As we had to grow several mothers together to get sufficient neonates for analysis, we were not able to directly link daughters' $\mathrm{P}$ content with that of their mothers. By randomly combining neonate/adult values, however, we found that the mass-specific P content of the low-P neonates was increased by a factor of 2 relative to their mothers, whereas for the high-P offspring this concentration effect was 1.5. As was the case for the body masses, we did not find significant differences in the body size of neonates from the different treatments (Table 2). However, the area of visible lipid droplets, a measure of energy storage, showed differences. The amount of storage material of neonates born at low-P food was more than double that of the high-P animals (Table 2).

In the growth experiment, we observed a significant three-way interaction between precultivation $\mathrm{P}$, actual P, and food concentration (Fig. 3). This was caused mainly by the animals cultured on the low food concentrations. Significant, precultivation-dependent differences in body growth could only be found at low concentrations of low-P food. Under these conditions, growth rates of neonates born at low $\mathrm{P}(0.038 \pm 0.003$ $\left.\mathrm{d}^{-1}\right)$ were higher than those of animals born from animals fed high-P algae $\left(-0.14 \pm 0.036 \mathrm{~d}^{-1}\right)(P=0.005$, Tukey hsd post hoc test following three-way ANOVA). In all other combinations of food quality and quantity, no such differences between animals from different precultures could be found. The growth rates obtained

TABLE 2. Summary table of the differences between mothers and daughters in the reproduction experiment.

\begin{tabular}{|c|c|c|c|c|c|}
\hline \multirow[b]{2}{*}{ Trait } & \multicolumn{2}{|c|}{$\mathrm{P}-$} & \multicolumn{2}{|c|}{$\mathrm{P}+$} & \multirow[b]{2}{*}{$P \dagger$} \\
\hline & Mean & SD & Mean & SD & \\
\hline Dry mass of mothers $(\mu \mathrm{g})$ & 275.0 & 45.6 & 526.2 & 80.0 & $<0.0001$ \\
\hline $\begin{array}{l}\text { Specific } \mathrm{P} \text { content of mothers } \\
\text { (\% of dry mass) }\end{array}$ & 0.40 & 0.12 & 0.64 & 0.27 & $<0.0004$ \\
\hline Dry mass of neonates $(\mu \mathrm{g})$ & 7.74 & 0.98 & 7.76 & 1.40 & NS \\
\hline $\begin{array}{l}\text { Specific } \mathrm{P} \text { content of neonates } \\
(\% \text { of dry mass })\end{array}$ & 0.72 & 0.13 & 0.94 & 0.22 & $<0.004$ \\
\hline Body size of neonates $(\mathrm{mm})$ & 0.88 & 0.01 & 0.86 & 0.03 & NS \\
\hline Lipid surface of neonates $\left(\mu \mathrm{m}^{2}\right)$ & 36.4 & 9.3 & 15.3 & 3.7 & $<0.001$ \\
\hline
\end{tabular}

$\dagger$ Two-tailed $t$ tests. 


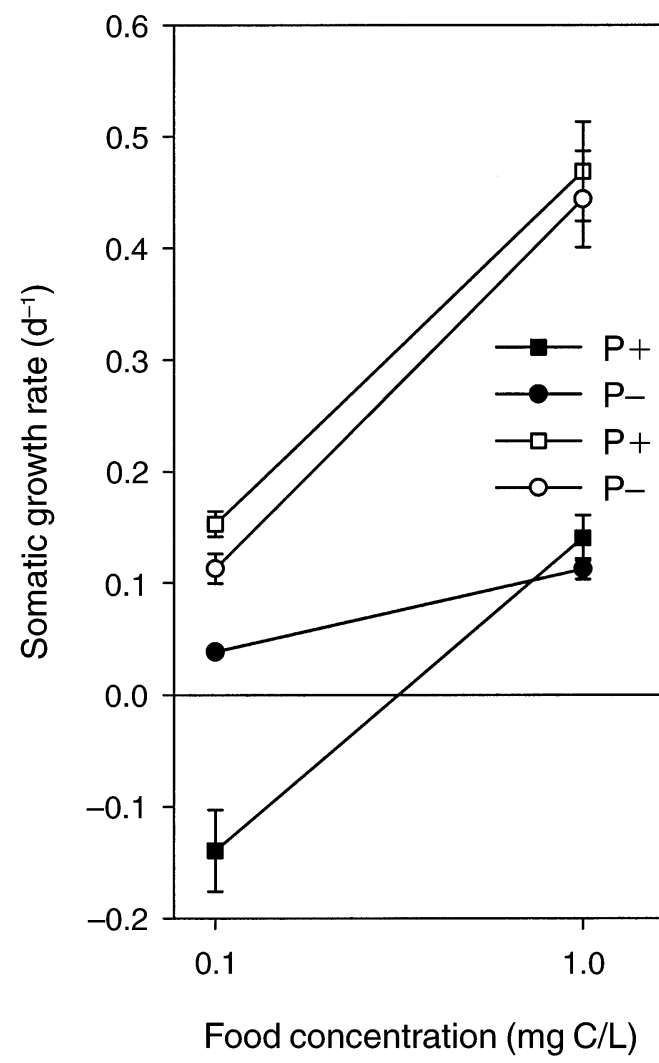

FIG. 3. Somatic growth rates of Daphnia magna neonates born from mothers that were cultured under high-phosphorus (squares) or low-phosphorus (circles) S. obliquus conditions, with the neonates cultured with low and high concentrations of high-P (open symbols) or low-P (solid symbols) S. obliquus, calculated for a 3-d period. Data are means of each three replicate vessels; error bars indicate $\pm \mathrm{SD}$.

for the low-P/high-quantity treatment were nearly identical to those reached with low quantities of high-P food.

\section{DISCUSSION}

Ecological stoichiometry theory has been applied successfully to explain differences in quality between different food sources, especially in aquatic systems (Sterner and Elser 2002). Nevertheless, the theory hinges on several assumptions, which have been shown not to be completely accurate. In this study we investigated the consequences of these violations of the assumptions underlying the current stoichiometry theory, using the cladoceran Daphnia magna as test organism.

Nutrients in short supply should be taken up and retained with near to $100 \%$ efficiency. Although this was suggested using models (e.g., Olsen et al. 1986), several studies, using a range of different organisms, have shown this not to be the case in insects (Slansky and Feeny 1977, Tabashnik 1982, Reynolds 1990), mammals (Partridge et al. 1989), fish (Schindler and Eby 1997), birds (Al-Masri 1995), copepods (LeBorgne 1986, Anderson and Hessen 1995), and cla- docerans (DeMott et al. 1998). The logical consequence of $100 \%$ nutrient retention is that at very low food levels only the energy content of the food should play a role, as this is needed for maintenance, but not the nutrient composition, as nutrients are needed for growth and production only, and all of the limiting nutrient is retained.

The basis for the stoichiometry models is a strict homeostasis in the consumer. However, even in aquatic systems where stoichiometric approaches have been primarily used, the homeostasis assumption does not seem to hold completely, and differences in the stoichiometry between animals of different sizes and ages have also been found (DeMott et al. 1998, Walve and Larsson 1999, Sterner and George 2000, Plath and Boersma 2001). This implies that animals might invest differentially in somatic and reproductive growth, and the consequences of this were investigated in this study.

\section{Nutrient content at low food}

Threshold food concentrations are an approximation of the basic metabolic demands of an animal derived from quantity-dependent growth rates, and consequently include costs of taking up and processing the food (specific dynamic action)(Gliwicz 1990, Kreutzer and Lampert 1999). Sterner and Robinson (1994) observed that threshold concentrations were independent of the mineral content of the food in Daphnia magna. In contrast, we found differences in threshold values between algae of different nutrient content as food for the same species. It is difficult to explain the differences between our results and those of Sterner and Robinson. There are several factors, however, that may have caused the high amount of unexplained variation in their experiments. First of all, the animals used in their study were not necessarily monoclonal. Secondly, the experiments were not standardized for the instar of the mother, yielding large differences in initial mass of the neonates. Thirdly, the lowest food levels were not considered as all of the animals died, which possibly caused an overestimation of the threshold values. As we avoided these difficulties, we conclude that even at low food levels not only is energy of importance, but the mineral content of the food plays a role as well. Mineral limitation in algae is normally accompanied by other changes apart from changes in nutrient content, such as the content of essential fatty acids (Müller-Navarra 1995), or structural changes reducing digestibility of the food (van Donk et al. 1997). These changes have been invoked to explain the differences in food quality, but the results of our supplementation treatment and of similar experiments reported in the literature (Urabe et al. 1997, 2002, DeMott et al. 1998, Boersma 2000, Elser et al. 2001, Plath and Boersma 2001) show that adding phosphorus to low-P algae increased growth rates up to levels reached with high-P food. Consequently, the 2-3 times higher $C_{0}$ values observed for 
the low-P algae were a direct effect of mineral limitation.

The difference between the threshold food concentrations of animals grown on high-P food vs. low-P food can be interpreted as a measure of the energy that is needed to deal with low-P food. Many consumers show an increase in feeding activity when faced with food with a low mineral content (e.g., Slansky and Feeny 1977, Reynolds 1990, Plath and Boersma 2001). This results in a decrease in the assimilation efficiency for the limiting nutrient, but an increase in the total amount of the nutrient taken up, thus optimizing nutrient acquisition (Reynolds 1990). Unfortunately, the studies investigating behavioral responses to changes in the mineral content were carried out with high concentrations of food, and it is difficult to assess whether these responses could also occur at much lower food levels (see Philippova and Postnov 1988, Plath 1998). If such responses could occur, then this would provide us with a mechanistic explanation of the observed phenomenon. An increase in feeding activity would imply an increase in energy spent on food uptake, which would reduce the growth efficiency and secondary production (Sterner and Hessen 1994), and would be measurable as higher threshold food concentrations.

An increase in feeding costs with decreasing mineral content of the food has consequences for existing models of the interactions between food quality and quantity (e.g., Sterner 1997). In this model the boundary between energy and mineral limitation is a dynamical function dependent on both the amount and the nutrient content of the food supplied. At a given quantity of food of a specific C:P ratio, the homeostatic consumer should shift from energy (below this quantity) to mineral limitation. This quantity is expected to decrease with an increasing $\mathrm{C}: \mathrm{P}$ ratio, i.e., to become lower with a lower mineral content of the food, reaching the asymptote of the threshold food concentration level, below which only energy limitation will play a role. We can use our data to investigate at which food concentration we can observe a significant difference between the growth rates of animals grown on high-P and low$\mathrm{P}$ algae, and use these concentrations as an estimate of Sterner's (1997) quality threshold. Interestingly, these food concentrations are below the quantity threshold calculated for the low-P Scenedesmus. In Sterner's model equations this was not possible, but it can be explained by quality-dependent shifts in $C_{0}$. Hence, we propose a more detailed separation of basal metabolic costs for further modeling of interactions between food quality and quantity. We assume that basic metabolic costs, such as the basal respiration rates (Bohrer and Lampert 1988), are unaffected by food quality. The total metabolic expenditure $\left(C_{0}\right)$, however, should then be calculated by adding costs of taking up and processing the food (specific dynamic action) to these basal metabolic costs. With decreasing food mineral content, costs of feeding should become more and more

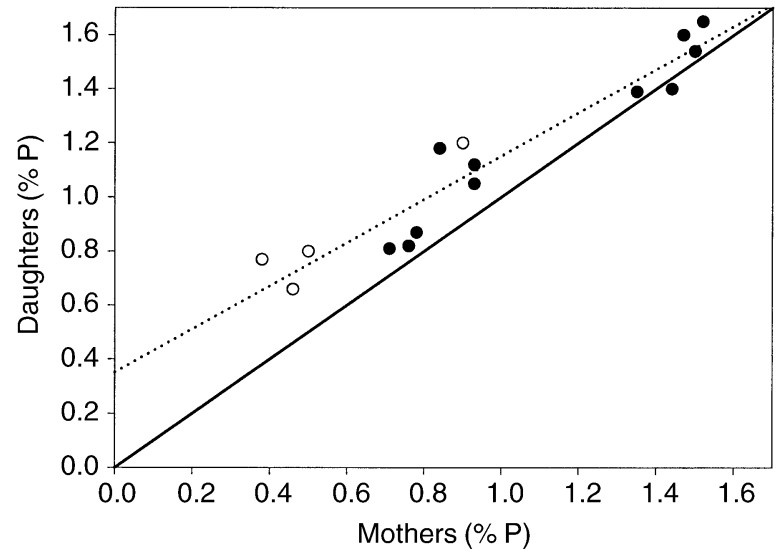

FIG. 4. Relationship between specific P content of adult Daphnia magna cultured at different qualities of food and their offspring. Data from our experiments (open circles) are plotted together with those given in DeMott et al. (1998) (solid circles). The solid line indicates a 1:1 ratio; the equation obtained from linear regression on all data points (dotted line) is: $Y=0.8 X+0.35\left(r^{2}=0.92\right)$.

pronounced and $C_{0}$ higher and higher. In contrast to the assumptions made in the original model, this means that the boundary between the transition of $\mathrm{C}$ and $\mathrm{P}$ limitation must not necessarily become infinite at the threshold level, but metabolic costs can reach values well above this transition (see also Urabe and Watanabe 1992).

\section{Investment in offspring}

Many studies have considered the effects of environmental conditions on the allocation of energy to reproduction on the one hand, and the division of the available energy into individual offspring on the other hand (e.g., Smith and Fretwell 1974, Stearns 1976, Winkler and Wallin 1987, Boersma 1995). Most of these studies, however, only used energy as the currency of interest (but see DeMott et al. 1998, Urabe and Sterner 2001). Here, we focused on the effects of nutrient content of the food, with the potential energy intake of the mothers being constant. We observed that mothers produce offspring that are richer in $\mathrm{P}$ than they are themselves. The same was found by DeMott et al. (1998). Others also observed that smaller Daphnia individuals had a higher $\mathrm{P}$ body content than larger ones (e.g., Main et al. 1997). This is usually explained by the higher maximum growth rates during the juvenile phase, linked with higher RNA requirements, and as this is the most important pool of phosphorus (Vrede et al. 1999), with higher P requirements. Only Sterner and Schulz (1998) reported lower mass-specific phosphorus contents in eggs than in their mothers, the mechanism of which is difficult to explain, especially since the carbon (energy) contents were not significantly different. If we plot our data with those provided by DeMott et al. (1998) (Fig. 4) this shows a clear deviation of the relation between the specific $\mathrm{P}$ content of 
daughters and their mothers from a proposed 1:1 ratio. Daughters generally have a higher mineral content than their mothers, and with decreasing mineral content of the food these differences become more and more pronounced. Daphniids grown on P-deficient food had a lower mass-specific P content, but they invested relatively more phosphorus into their offspring than the high-P animals. As high-P neonates still have a higher specific $\mathrm{P}$ content, this does not sufficiently explain the growth rate differences that we found at low concentrations of poor food (Fig. 3). Although mothers reared at low-P food were significantly lighter than their high$P$ sisters, their offspring did not differ in mass, and had more visible lipid droplets than the offspring produced by high-P mothers (Table 2). Whereas at low food quantities, additional energy will help the animals to overcome starvation periods (Boersma 1997b), at low $\mathrm{P}$ it could help neonates to cope with costs coming along with increased food uptake. In fact, in their recent study, Urabe and Sterner (2001) also observed that eggs produced by $\mathrm{P}$-limited mothers contained more reserve substances. This increase in energy reserves could explain the differences in body growth rates that we found at low concentrations of poor food, as this might have provided the energy for an increased $\mathrm{P}$ uptake.

\section{Conclusions}

In this study, we have investigated the consequences of some violations of the assumptions underlying the current ecological stoichiometry theory. We have shown that even at very low food levels quality differences between different food sources influence growth rates for Daphnia magna. In contrast to the predictions of Sterner and Robinson (1994), we found quality-dependent shifts in threshold food concentrations. Moreover, we have also shown that even animals that show a large amount of homeostasis are capable of differentially investing nutrients between somatic growth and reproduction. Our results illustrate the importance of incorporating low levels of food into the current models.

\section{ACKNOWLEDGMENTS}

We thank Heinke Buhtz and Catherine Schmuck for their assistance during the experiments. Claudia Schöps, Ed McCauley, Klaus Plath, Karen Wiltshire, Bob Sterner, Bill DeMott, Winfried Lampert, Tim Wootton, and one anonymous reviewer are thanked for stimulating discussions and fruitful comments on earlier versions of this manuscript. M. Boersma was partly supported by DFG Grant BO 1488/3-1, and contract ENV4-CT97-0402 (SNIFFS) within the framework of the European Commission's Environment and Climate Program.

\section{Literature Cited}

Al-Masri, M. R. 1995. Absorption and endogenous excretion of phosphorus in growing broiler chicks, as influenced by calcium and phosphorus ratios in feed. British Journal of Nutrition 74:407-415.

Andersen, T. 1997. Pelagic nutrient cycles; herbivores as sources and sinks. Springer, Berlin, Germany.

Anderson, T. R. 1992. Modelling the influence of food C:N ratio, and respiration on growth and nitrogen excretion in marine zooplankton and bacteria. Journal of Plankton Research 14:1645-1671.

Anderson, T. R., and D. O. Hessen. 1995. Carbon or nitrogen limitation in marine copepods? Journal of Plankton Research 17:317-331.

Anderson, T. R., and D. W. Pond. 2000. Stoichiometric theory extended to micronutrients: comparison of the roles of essential fatty acids, carbon, and nitrogen in the nutrition of marine copepods. Limnology and Oceanography 45:11621167.

Boersma, M. 1995. The allocation of resources to reproduction in Daphnia galeata: against the odds? Ecology 76: 1251-1261.

Boersma, M. 1997a. Offspring size and parental fitness in Daphnia magna. Evolutionary Ecology 11:439-450.

Boersma, M. 1997b. Offspring size in Daphnia: does it pay to be overweight? Hydrobiologia 360:79-88.

Boersma, M. 2000. The nutritional quality of P-limited algae for Daphnia. Limnology and Oceanography 45:1157-1161.

Bohrer, R. N., and W. Lampert. 1988. Simultaneous measurement of the effect of food concentration on assimilation and respiration in Daphnia magna Straus. Functional Ecology 2:463-471.

Bradley, M. C., N. Perrin, and P. Calow. 1991. Energy allocation in the cladoceran Daphnia magna Straus, under starvation and refeeding. Oecologia 86:414-418.

Congdon, J. D., and J. W. Gibbons. 1987. Morphological constraint on egg size: a challenge to optimal egg size theory? Proceedings of the National Academy of Sciences (USA) 84:4145-4147.

DeMott, W. R. 1998. Utilization of a cyanobacterium and a phosphorus-deficient green alga as complementary resources by daphnids. Ecology 79:2463-2481.

DeMott, W. R., and R. D. Gulati. 1999. Phosphorus limitation in Daphnia: evidence from a long term study of three hypereutrophic Dutch lakes. Limnology and Oceanography 44:1557-1564.

DeMott, W. R., R. D. Gulati, and K. Siewertsen. 1998. Effects of phosphorus-deficient diets on the carbon and phosphorus balance of Daphnia magna. Limnology and Oceanography 43:1147-1161.

Elser, J. J., D. R. Dobberfuhl, N. A. Mackay, and J. H. Schampel. 1996. Organism size, life history, and N:P stoichiometry. BioScience 46:674-684.

Elser, J. J., W. F. Fagan, R. F. Denno, D. R. Dobberfuhl, A. Folarin, A. Huberty, S. Interlandi, S. S. Kilham, E. McCauley, K. L. Schulz, E. H. Siemann, and R. W. Sterner. 2000. Nutritional constraints in terrestrial and freshwater food webs. Nature 408:578-580.

Elser, J. J., and R. P. Hassett. 1994. A stoichiometric analysis of the zooplankton-phytoplankton interaction in marine and freshwater ecosystems. Nature 370:211-213.

Elser, J. J., K. Hayakawa, and J. Urabe. 2001. Nutrient limitation reduces food quality for zooplankton: Daphnia response to seston phosphorus enrichment. Ecology 82:898903.

Elser, J. J., and J. Urabe. 1999. The stoichiometry of consumer-driven nutrient recycling: theory, observations, and consequences. Ecology 80:735-751.

Glazier, D. S. 2000. Is fatter fitter? Body storage and reproduction in ten populations of the freshwater amphipod Gammarus minus. Oecologia 122:335-345.

Gliwicz, Z. M. 1990. Food thresholds and body size in cladocerans. Nature 343:638-640.

Grimm, N. B. 1988. Feeding dynamics nitrogen budgets and ecosystem role of a desert stream omnivore Agosia chrysogaster Pisces Cyprinidae. Environmental Biology of Fishes 21:143-152. 
Hessen, D. O. 1992. Nutrient element limitation of zooplankton production. American Naturalist 140:799-814.

Joern, A., and S. T. Behmer. 1998. Impact of diet quality on demographic attributes in adult grasshoppers and the nitrogen limitation hypothesis. Ecological Entomology 23: $174-184$.

Kilham, S. S., D. A. Kreeger, C. E. Goulden, and S. G. Lynn. 1997. Effects of algal food quality on fecundity and population growth rates of Daphnia. Freshwater Biology 38: 639-647.

Klüttgen, B., U. Dulmer, M. Engels, and H. T. Ratte. 1994. ADaM, an artificial freshwater for the culture of zooplankton. Water Research 28:743-746.

Kooijman, S. A. L. M. 1995. The stoichiometry of animal energetics. Journal of Theoretical Biology 177:139-149.

Kooijman, S. A. L. M. 2000. Dynamic energy and mass budgets in biological systems. Second edition. Cambridge University Press, Cambridge, UK.

Kreutzer, C., and W. Lampert. 1999. Exploitative competition in differently sized Daphnia species: a mechanistic explanation. Ecology 80:2348-2357.

Lack, D. 1947. The significance of clutch size. Ibis 89:309352.

Lampert, W. 1977. Studies on the carbon balance of Daphnia pulex de Geer as related to environmental conditions. IV. Determination of the "threshold" concentration as a factor controlling the abundance of zooplankton species. Archiv für Hydrobiologie Supplement 48:361-368.

Lampert, W., R. D. Schmitt, and P. Muck. 1988. Vertical migration of freshwater zooplankton: test of some hypotheses predicting a metabolic advantage. Bulletin of Marine Science 43:620-640.

Lampert, W., and I. Trubetskova. 1996. Juvenile growth rate as a measure of fitness in Daphnia. Functional Ecology 10: 631-635.

LeBorgne, R. 1986. The release of soluble end products of metabolism. Pages 109-164 in D. S. Corner and S. C. M. O'Hara, editors. The biological chemistry of Marine Copepods. Oxford University Press, Oxford, UK.

Main, T. M., D. R. Dobberfuhl, and J. J. Elser. 1997. N:P stoichiometry and ontogeny of crustacean zooplankton: a test of the growth rate hypothesis. Limnology and Oceanography 42:1474-1478.

McCauley, E., W. W. Murdoch, R. M. Nisbet, and W. S. C. Gurney. 1990. The physiological ecology of Daphnia: development of a model of growth and reproduction. Ecology 71:703-715.

Müller-Navarra, D. C. 1995. Evidence that a highly unsaturated fatty acid limits Daphnia growth in nature. Archiv für Hydrobiologie 132:297-307.

Nager, R. G., C. Rügger, and A. J. van Noordwijk. 1997. Nutrient or energy limitation on egg formation-a feeding experiment in great tits. Journal of Animal Ecology 66: 495-507.

Olsen, Y., A. Jensen, H. Reinertsen, K. Y. Borsheim, M. Heldal, and A. Langeland. 1986. Dependence of the rate of release of phosphorus by zooplankton on the $\mathrm{P}: \mathrm{C}$ ratio in the food-supply, as calculated by a recycling model. Limnology and Oceanography 31:34-44.

Partridge, G. G., P. H. Garthwaite, and M. Findlay. 1989. Protein and energy retention by growing rabbits offered diets with increasing proportions of fiber. Journal of Agricultural Science 112:171-178.

Philippova, T. G., and A. L. Postnov. 1988. The effect of food quantity on feeding and metabolic expenditure in Cladocera. Internationale Revue der gesamten Hydrobiologie 73:601-615.

Plath, K. 1998. Adaptive feeding behavior of Daphnia magna in response to short-term starvation. Limnology and Oceanography 43:593-599.
Plath, K., and M. Boersma. 2001. Mineral limitation of zooplankton: stoichiometric constraints and optimal foraging. Ecology 82:1260-1269.

Raubenheimer, D., and S. J. Simpson. 1998. Nutrient transfer functions: the site of integration between feeding behaviour and nutritional physiology. Chemoecology 8:61-68.

Reynolds, S. E. 1990. Feeding in caterpillars: maximizing or optimizing nutrient acquisition. Pages 106-118 in J. Mellinger, editor. Animal nutrition and transport processes. 1. Nutrition in wild and domestic animals. Karger, Basel, Switzerland.

Roman, M. R. 1983. Nitrogenous nutrition of marine invertebrates. Pages 347-383 in E. J. Carpenter and D. G. Capone, editors. Nitrogen in the marine environment. Academic Press, London, UK.

Rothhaupt, K. O. 1995. Algal nutrient limitation affects rotifer growth rate but not ingestion rate. Limnology and Oceanography 40:1201-1208.

Schindler, D. E., and L. A. Eby. 1997. Stoichiometry of fishes and their prey: implications for nutrient recycling. Ecology 78:1816-1831.

Schoener, T. W. 1971. Theory of feeding strategies. Annual Review of Ecology and Systematics 2:369-404.

Slansky, F., and P. Feeny. 1977. Stabilization of the rate of nitrogen accumulation by larvae of the cabbage butterfly on wild and cultivated food plants. Ecological Monographs 47:209-228.

Smith, C. C., and S. D. Fretwell. 1974. The optimal balance between size and number of offspring. American Naturalist 108:499-506.

Stearns, S. C. 1976. Life-history tactics: a review of the ideas. Quarterly Review of Biology 51:3-47.

Sterner, R. W. 1997. Modelling interactions of food quality and quantity in homeostatic consumers. Freshwater Biology 38:473-481.

Sterner, R. W., J. Clasen, W. Lampert, and T. Weisse. 1998. Carbon: phosphorus stoichiometry and food chain production. Ecology Letters 1:146-150.

Sterner, R. W., and J. J. Elser. 2002. Ecological stoichiometry: the biology of elements from molecules to the biosphere. Princeton University Press, Princeton, New Jersey, USA.

Sterner, R. W., and N. B. George. 2000. Carbon, nitrogen, and phosphorus stoichiometry of cyprinid fishes. Ecology 81:127-140.

Sterner, R. W., and D. O. Hessen. 1994. Algal nutrient limitation and the nutrition of aquatic herbivores. Annual Review of Ecology and Systematics 25:1-29.

Sterner, R. W., and J. L. Robinson. 1994. Thresholds for growth in Daphnia magna with high and low phosphorus diets. Limnology and Oceanography 39:1228-1232.

Sterner, R. W., and K. L. Schulz. 1998. Zooplankton nutrition: recent progress and a reality check. Aquatic Ecology 32:261-279.

Sugiura, S. H., F. M. Dong, and R. W. Hardy. 2000. A new approach to estimating the minimum dietary requirement of phosphorus for large rainbow trout based on nonfecal excretions of phosphorus and nitrogen. Journal of Nutrition 130:865-872.

Tabashnik, B. E. 1982. Responses of pest and non-pest Colias butterfly larvae to intraspecific variation in leaf nitrogen and water content. Oecologia 55:389-394.

Thingstad, T. F. 1987. Utilization of N, P, and organic C by heterotrophic bacteria. I. Outline of a chemostat theory with a consistent concept of 'maintenance' metabolism. Marine Ecology Progress Series 35:99-109.

Touratier, F., J. G. Field, and C. L. Moloney. 2001. A stoichiometric model relating growth substrate quality $(\mathrm{C}: \mathrm{N}: \mathrm{P}$ ratios) to $\mathrm{N}: \mathrm{P}$ ratios in the products of heterotrophic release and excretion. Ecological Modelling 139:265-291. 
Urabe, J., J. Clasen, and R. W. Sterner. 1997. Phosphorus limitation of Daphnia growth: is it real? Limnology and Oceanography 42:1436-1443.

Urabe, J., M. Kyle, W. Makino, T. Yoshida, T. Andersen, and J. J. Elser. 2002. Reduced light increases herbivore production due to stoichiometric effects of light:nutrient balance. Ecology 83:619-627.

Urabe, J., and R. W. Sterner. 2001. Contrasting effects of different types of resource depletion on life-history traits in Daphnia. Functional Ecology 15:165-174.

Urabe, J., and Y. Watanabe. 1992. Possibility of N-limitation or P-limitation for planktonic cladocerans-an experimental test. Limnology and Oceanography 37:244-251.

Urabe, J., and Y. Watanabe. 1993. Implications of sestonic elemental ratio in zooplankton ecology - reply. Limnology and Oceanography 38:1337-1340.

Van Donk, E., M. Lürling, D. O. Hessen, and G. M. Lokhorst. 1997. Altered cell wall morphology in nutrient-deficien phytoplankton and its impact on grazers. Limnology and Oceanography 42:357-364.
Vos, J. H., M. A. G. Ooijevaar, J. F. Postma, and W. Admiraal. 2000. Interaction between food availability and food quality during growth of early instar chironomid larvae. Journal of the North American Benthological Society 19:158-168.

Vrede, T., T. Andersen, and D. O. Hessen. 1999. Phosphorus distribution in three crustacean zooplankton species. Limnology and Oceanography 44:225-229.

Walve, J., and U. Larsson. 1999. Carbon, nitrogen and phosphorus stoichiometry of crustacean zooplankton in the Baltic Sea: implications for nutrient recycling. Journal of Plankton Research 21:2309-2321.

White, T. C. R. 1993. The inadequate environment. Springer Verlag, Berlin, Germany.

Winkler, D. W., and K. Wallin. 1987. Offspring size and number: a life history model linking effort per offspring and total effort. American Naturalist 129:708-720.

Zehnder, A. A., and P. R. Gorham. 1960. Factor influencing the growth of Microcystis aeruginosa Kütz. emend. Elenk. Canadian Journal of Microbiology 6:645-660. 